\title{
TOPONIMIA DE LA CARTA DE POBLACIÓN DE EJEA DE LOS CABALLEROS (JULIO DE 1110)
}

\author{
TOPONYMY OF THE «CARTA DE POBLACIÓN»OF \\ EJEA DE LOS CABALLEROS (JULY 1110)
}

Marcelino Cortés Valenciano

Resumen: El artículo estudia los nombres de lugar mencionados en la Carta de Población de Ejea de los Caballeros (Zaragoza) otorgada por el rey Alfonso I en julio de 1110. En primer lugar, situamos estos nombres de manera precisa sobre el territorio, determinando el orden en el que se relacionan en el documento. En segundo lugar, proporcionamos una explicación semántica y formal a los topónimos. El estudio toponomástico permite reconstruir no sólo cuál era la situación del territorio recién conquistado a comienzos del siglo XII, sino también mostrar aspectos relativos a la distribución poblacional del lugar durante las centurias anteriores.

Palabras clave: Toponimia, Carta de Población, Ejea de los Caballeros.

\begin{abstract}
This article studies the aforementioned place names in the «Carta de Población» of Ejea de los Caballeros (Saragossa) granted by King Alfonso I in July 1110. Firstly, we place these names in the territory in an accurate way, fixing the order in which they appear in the document. Secondly, we give a semantic and formal explanation of the toponyms. The toponymic study allows us not only to reconstruct the situation of the recently conquered territory at the beginning of the 12th century, but also to show some aspects related to the distribution of the population in the place in the previous centuries.
\end{abstract}

Keywords: Toponymy, Carta de Población, Ejea de los Caballeros. 


\section{INTRODUCCIÓN}

La historia medieval de la villa de Ejea de los Caballeros se inaugura plenamente en el mes de julio del año 1110 con dos documentos trascendentales otorgados por el rey Alfonso I que constituyen las actas fundacionales del municipio: el primero es el llamado Fuero de Ejea (Carta de ingenuidad y franqueza concedida por Alfonso I a los pobladores, presentes y futuros, de Ejea de los Caballeros) y el segundo es la denominada Carta de Población de Ejea (Carta de Población de Ejea dada por el rey Alfonso I en el que se delimita el término municipal y se concede el derecho de escaliar dentro de los limites asignados) $)^{1}$.

Ambos documentos aparecen recogidos en las principales compilaciones documentales de la época y son objeto de referencia por parte de los principales trabajos historiográficos que se ocupan del estudio de la Edad Media en la Corona de Aragón ${ }^{2}$. El hecho de que ambos compartan la misma fecha — julio de 1110 — ha ido forjando la tradición de citarlos y estudiarlos a la vez.

Así ocurre, por ejemplo, en el primer trabajo (2003) que se ocupó de una manera monográfica del estudio de ambos documentos a cargo de Ana Isabel Lapeña (estudio y transcripción) y M. ${ }^{\mathrm{a}}$ del Mar Agudo (traducción y glosario $)^{3}$.

En el año 2005 estas mismas autoras editaron y estudiaron pormenorizadamente el documento que nos ocupa en el marco de las publicaciones conmemorativas del IX aniversario de la incorporación de la villa de Ejea

1.- No entramos en la cuestión denominativa de ambos documentos, ni tampoco en la idoneidad de la denominación que utilizamos en el trabajo. El marbete Carta de población que preside el título y que se utilizará a lo largo de las páginas siguientes debe entenderse como una convención más del estudio. Para todo lo relativo a esta cuestión remito a la introducción de M. ${ }^{a}$ Luisa Ledesma Rubio (ed.), Cartas de población del Reino de Aragón en los siglos medievales, Zaragoza, Institución «Fernando el Católico», Fuentes Históricas Aragonesas, 1991, pp. 16-17.

2.- El documento aparece reproducido por José María LACARra (ed.), Documentos para el estudio de la Reconquista y repoblación del Valle del Ebro, vol. I, Zaragoza, Anubar, Textos medievales, 1982, doc. 40; por José Ángel Lema Pueyo (ed.), Colección diplomática de Alfonso I de Aragón y Pamplona (1104-1134), San Sebastián, Eusko Ikastuntza, Fuentes documentales del País Vasco, 1990, doc. 42; y por M. ${ }^{a}$ L. Ledesma, ob. cit., doc. 25.

3.- Ana Isabel Lapeña Paúl \& M. ${ }^{a}$ del Mar Agudo Romeo, El fuero de Ejea de los Caballeros y su difusión, Diputación Provincial de Zaragoza, Justicia de Aragón e Ibercaja, Zaragoza, 2003. Como señala la primera de estas autoras en su estudio, "la repoblación de los lugares que se emprendió desde la segunda mitad del siglo XI en adelante se iniciaba con una carta de población, lo que genéricamente suele denominarse carta puebla, donde se especifica el territorio concedido, seguido de las concesiones determinadas que la monarquía, o el señor, ya fuera laico, ya eclesiástico otorgaba, que es lo que pueden considerarse privilegios [...]. En el caso de Ejea todo ello se conserva en dos documentos, no originales, separados, pero que deben ser considerados como uno sólo" (p. 47). 
de los Caballeros a la Corona de Aragón ${ }^{4}$, tradicionalmente fechada en el año $1105^{5}$.

En este último trabajo el estudio de la Carta de Población se estructura en seis apartados:

a) Otorgante.

b) Datación y lugar de concesión.

c) Contenido.

d) Características del pergamino.

e) Otras copias.

f) Ediciones y traducciones.

De todos estos apartados el que se ciñe a nuestro estudio es el que ocupa el tercer lugar. En él se ofrece una descripción general de los topónimos mencionados en el documento, señalándose que "algunos pertenecen a poblaciones que existen actualmente, pero otros están despoblados"6.

En esta descripción se determina básicamente el orden en el que se mencionan los topónimos en el documento. Su ubicación geográfica, sin embargo, es desigual: unos se sitúan con precisión por ser topónimos actualmente con vigencia apelativa y presentar similitudes formales que posibilitan su reconocimiento (Annesa, Arripas, Barchaona, Bardena, Canals, Castillon de Baldiassa, Escoron, Fraxino de rio de Aonna, Fraxino de rio de Ores, illo Baio, Sentia y Torr de Sentia); otros se ubican de manera genérica (Almalel, Arripa Roia, capeza d'Aquisillo, Fraxinat, Fraxinatello, Torr Longa); otros se localizan de manera errónea (Gorria $)^{7}$.

4.- M. a del Mar Agudo Romeo \& Ana Isabel Lapeña Paúl (eds.), Joyas del Patrimonio Documental de la Villa de Ejea de los Caballeros, Diputación Provincial de Zaragoza y Ayuntamiento de Ejea de los Caballeros, Ejea de los Caballeros, Imprenta Félix Arilla. La primera parte, en la que se estudia el Fuero de Ejea, corre a cargo de A. I. LAPEÑA (pp. 7-30); la segunda parte está elaborada por M. ${ }^{2}$ M. Agudo dentro del capítulo II titulado «Los dos pergaminos más antiguos del Archivo Histórico Municipal de Ejea» (pp. 31-52). En este capítulo la Carta de Población se estudia conjuntamente con un documento fechado en octubre de 1134 mediante el cual el rey Ramiro II concede a los pobladores de Ejea una salina para que la tengan en propiedad (Archivo Municipal de Ejea de los Caballeros, A.4.I I; AHME de aquí en adelante).

5.- Sobre la fecha de la conquista de Exea vid. el estado de la cuestión que recoge José Ángel LEMA Pueyo, Alfonso I el Batallador, rey de Aragón y Pamplona (1104-1134), Gijón, Trea, 2008. Como señala este autor, "la prudencia aconsejaría señalar un amplio margen cronológico en el que pudo haber caído Ejea, al menos de un año de acoso intermitente, contando a partir del otoño de 1105 hasta noviembre de $1106 "$ (p. 60).

6.- M. ${ }^{a}$ M. Agudo \& A. I. Lapeña (eds.), Joyas del Patrimonio, ob. cit., p. 37. El resumen que a continuación realizamos debe entenderse como un pequeño y compendioso estado de la cuestión.

7.- Esta identificación de los topónimos mencionados en el documento es mucho más escueta e imprecisa en A.I. Lapeña \& M. ${ }^{a}$ M. Agudo, El fuero de Ejea de los Caballeros, ob. cit., pp. 42-45. 
Expuesto lo anterior, nuestro trabajo tiene dos objetivos principales: por un lado, situar geográficamente de una manera precisa todos los topónimos citados en la Carta de Población, mostrando sus correlatos actuales en aquellos que perviven en la actualidad e indagando las causas por las que otros fueron desapareciendo a lo largo de los siglos; por otro, proporcionar una explicación lingüística - formal y semántica - a los nombres de lugar que se relacionan en el documento.

Como podremos comprobar en las conclusiones finales, el estudio toponomástico de la Carta de Población de Ejea de los Caballeros no sólo ofrece una imagen de la situación del territorio recién conquistado, sino que también permite mostrar aspectos relativos a la distribución poblacional del lugar durante las centurias anteriores.

\section{El CORPUS TOPONÍMICO}

A continuación reproducimos el segundo bloque de la Carta de Población - la dispositio del documento- en donde se relacionan los términos que integran y delimitan el término municipal de Exea con el objeto de fijar el corpus toponímico que va a ser analizado, así como para determinar posteriormente el orden seguido en la enumeración ${ }^{8}$ :

In Dei nomine et eius diuina clementia, Patris et Filii et Spiritus Sancti, amen. Ego Adefonssus, Dei gratia imperator, facio hanc cartam donationis et confirmationis vobis populatores de Exeia, qui estis uel qui de ista ora in antea ueneritis ibi populare, de omnibus terminis vestris de Barchaona usque ad Castillon de Baldiassa; et de illo castillon usque ad Sentia, et de Sentia usque ad illo Fraxino de rio de Ores, et de Fraxino de rio de Ores usque ad illo Fraxino de rio de Aonna, et de Aonna usque ad Arripa Roia, et de Rripa Roia usque a la capeza d'Aquisillo, et similiter illa Bardena tota usque ad Barchaona quomodo aqua uertit. Et illa Torr de Escoron non habet nisi VII iuvatas, toto alio termino ab integro de Exeia. Similiter illa Torr de Canals, VI iuvatas. Et illa Torr de Annessa IIII ${ }^{\text {or }}$, toto alio de Exeia. Et illa Torr Longa II $^{\text {as }}$ iuvatas. Et Fraxinatello III $^{\text {es }}$, alio termino de Exeia. Alio Fraxinat de super V iuvatas. Almalel $\mathrm{II}^{\text {as }}$ iuvatas, toto alio de

8.- AHME, A.4.7. Los topónimos se marcan en cursiva. Seguimos la transcripción realizada por M. ${ }^{\mathrm{a}} \mathrm{M}$. Agudo \& A. I. Lapeña (eds.), Joyas del Patrimonio, ob. cit., p. 45. Como refiere la primera de las autoras en su estudio (pp. 38-39), el documento que se guarda en el Archivo Histórico Municipal de Ejea de los Caballeros no es el original, pero es la copia más antigua que se conserva, datándose en el siglo XII. En el Archivo de la Corona de Aragón se encuentran otras tres copias más tardías del documento que recogen distintas variantes en la transcripción de los topónimos. Todas estas variantes aparecen recogidas y sistematizadas en A.I. LAPEÑA \& M. ${ }^{a}$ M. AGUDO, El fuero de Ejea de los Caballeros, ob. cit., 124-125. 
Exeia. Et illa Tor de Sentia III $^{\text {es }}$. Et illa Torr de Arripas IIII $^{\text {or }}$, toto alio de Exeia. Et in Gorria II $^{\text {as }}$ iuvatas, toto alio de Exeia. Et illo Baio X iuvatas, toto alio de Exeia.

\section{EL ORDEN DE LA ENUMERACIÓN}

La relación de lugares que se mencionan en el documento, lejos de ser una enumeración caótica o azarosa, se rige por un estricto orden enumerativo que es posible desentrañar mediante la identificación rigurosa de los topónimos.

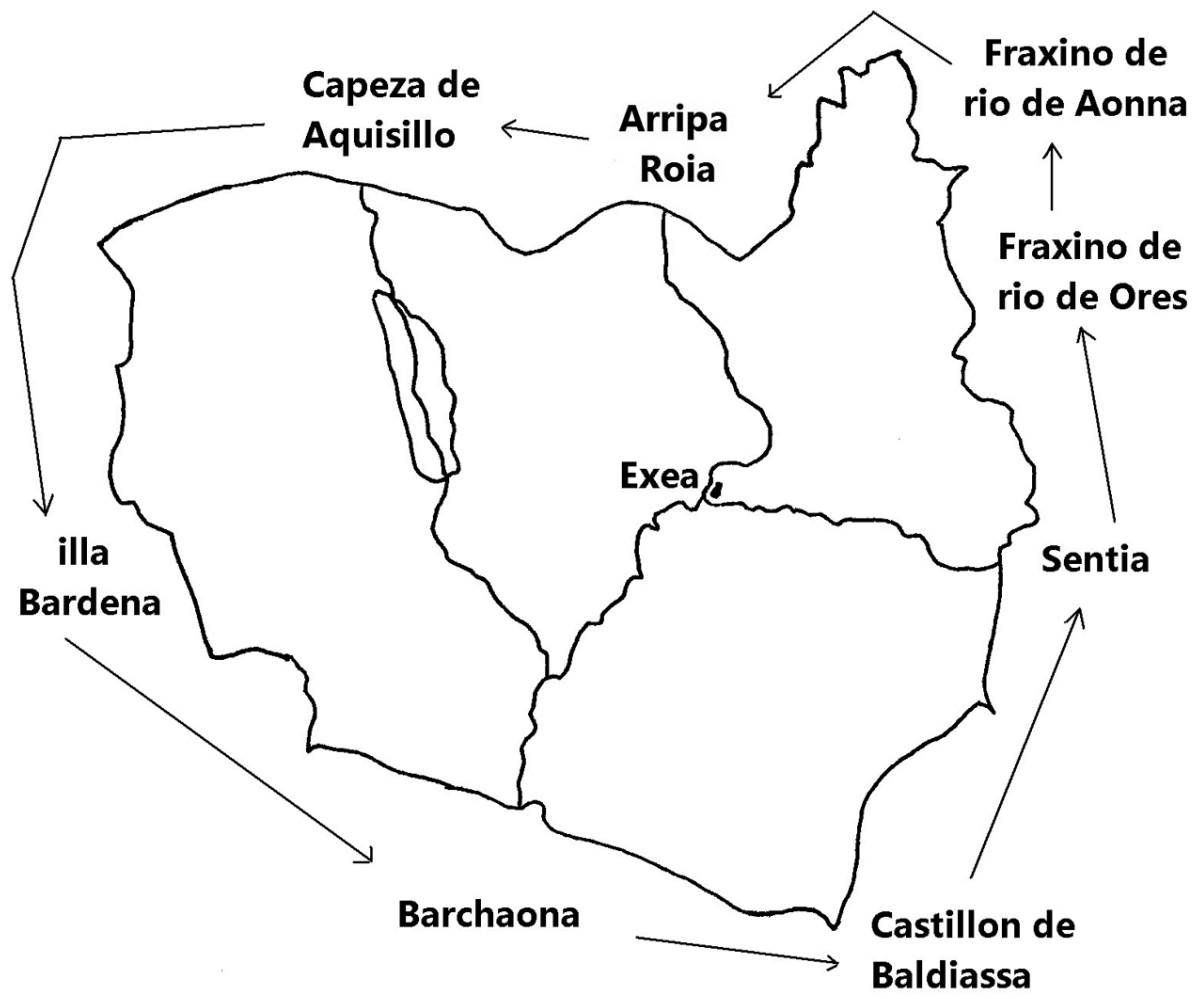

Mapa 1. Topónimos de perímetro mencionados en la Carta de Población de 1110.

En esta enumeración se observan tres bloques muy definidos.

En primer lugar, se enumeran los topónimos que delimitan el perímetro del territorio de Exea. Esta enumeración comienza por el sur del municipio 
con el topónimo Barchaona — conservado en la actualidad como Barcabona o Valcabona - que se sitúa junto al río Arba en el límite entre las actuales villas de Ejea de los Caballeros y Tauste. La relación continúa hacia el sudeste (Castillon de Baldiassa, actual Castejón de Valdejasa) y después se dirige hacia el norte (Sentia, actual Santia). A continuación se enumeran los topónimos que trazan el límite por el norte a través de la intersección del límite territorial que se establece con los distintos cursos de agua que surcan el territorio (Fraxino de rio de Ores, Fraxino de rio de Aonna, Arripa Roia, capeza de Aquissillo, ninguno de los cuales cuenta con correlato toponímico actual). Este primer bloque se cierra con la descripción del oeste del término, íntegramente cubierto por illa Bardena (La Bardena), regresando de nuevo al punto de inicio (Barchaona).

El recorrido efectuado nos señala cómo la enumeración de los topónimos de perímetro de la Carta de Población describe un círculo en dirección contraria a las agujas del reloj, tal y como se puede observar en el mapa 1:

El segundo bloque enumerativo está formado por una serie de topónimos que tienen en común el apelativo torre como elemento nuclear ${ }^{9}$.

Este apelativo concreta su significación bien mediante un adyacente preposicional (Torr de Escoron, Torr de Canals, Torr de Annessa, Torr de Arripas, Torr de Sentia), o bien mediante un adyacente adjetival (Torr Longa). Perdido el elemento nuclear, los topónimos de la primera modalidad han perdurado en el tiempo a través de su término preposicional correspondiente (Escorón, Canales, Añesa, Rivas, Santia); por el contrario, el topónimo Torr Longa carece de vigencia apelativa ya que, como veremos más adelante, ha sido objeto de una retoponimización.

$\mathrm{Al}$ igual que en el bloque anterior, el documento comienza la relación por el sur (Torr de Escoron) y va remontando hacia el norte en sentido contrario al curso del río Arba (Torr de Canals, Torr de Annessa, Torr Longa). Después se dirige hacia el este (Torr de Sentia) y se cierra con la torre más septentrional de todas (Torr de Arripas).

En tercer y último lugar, se enumeran los topónimos que señalan determinados enclaves del interior del término municipal que, al igual que las torres

9.- A propósito de estas torres A. I. LAPEÑa señala en El fuero de Ejea de los Caballeros (ob. cit., p. 42) lo siguiente: "Dentro de esta delimitación, que parece ser amplia, se asentaban diversas torres, posiblemente antiguas pequeñas fortalezas islámicas reaprovechadas y renovadas por los cristianos, y también otras entidades de población con su términos. Cada una de ellas tenía, a su vez, asignada una superficie de la cual obtendrían sus dueños y tenentes, a veces la propia monarquía, sus rentas, por lo que era necesario precisar exactamente los espacios que quedaban adscritos a los habitantes de Ejea en cada una de las demarcaciones y los que eran de otra propiedad". 
anteriores, quedaban fuera de los espacios adscritos a los habitantes de Exea por pertenecer a otra propiedad y a las cuales se les asignan las correspondientes yugadas de extensión ${ }^{10}$.

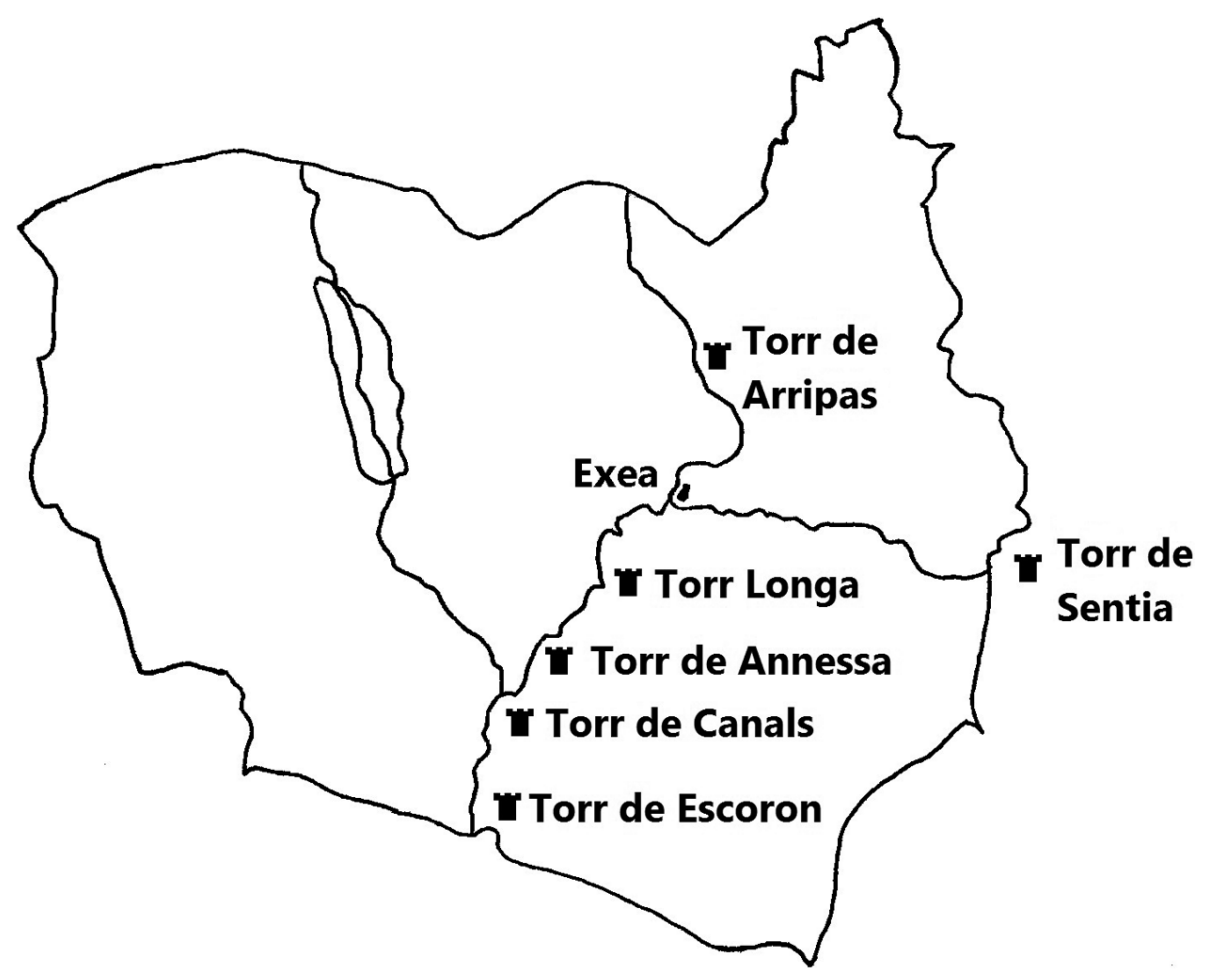

Mapa 2. Topónimos defensivos: las torres mencionadas en la Carta de Población de 1110.

Se comienza con los que están situados más al este (Fraxinat, Fraxinatiello y Almalel); de los tres sólo se conserva en la actualidad el primero de ellos bajo las denominaciones deformadas por la asociación paronomástica de Los Frajinetes o Los Fajinetes. Después se desplaza al oeste y se citan los dos últimos topónimos del documento: illo Baio y Gorria.

10.- Como señala A. I. LAPEÑA, "nada se dice de a quién pertenecían dichas yugadas, si el rey las había concedido a sus colaboradores, algo habitual por otra parte, o bien se las había reservado" (ibídem, p. 44). 
El topónimo illo Baio se corresponde con el actual despoblado de El Bayo, nombre también con el que a mediados del siglo XX fue bautizado el actual barrio de colonización.

Gorria o Gorreia es un topónimo que ha dado lugar a equívocos y a localizaciones muy alejadas del ámbito espacial que consideramos, ya que de su evolución lingüística deriva Gurrea, resultado que se ha identificado con la localidad del mismo nombre en Huesca (Gurrea de Gállego) ${ }^{11}$. El topónimo Gorria (> Gurrea) ha pervivido hasta la Edad Moderna bajo la forma El Salobrar de Gurrea. De acuerdo a este dato que más adelante desarrollaremos, el topónimo Gorria se localiza al sur del municipio, en los terrenos fronterizos con Tauste que están situados en la margen derecha del río Arba.

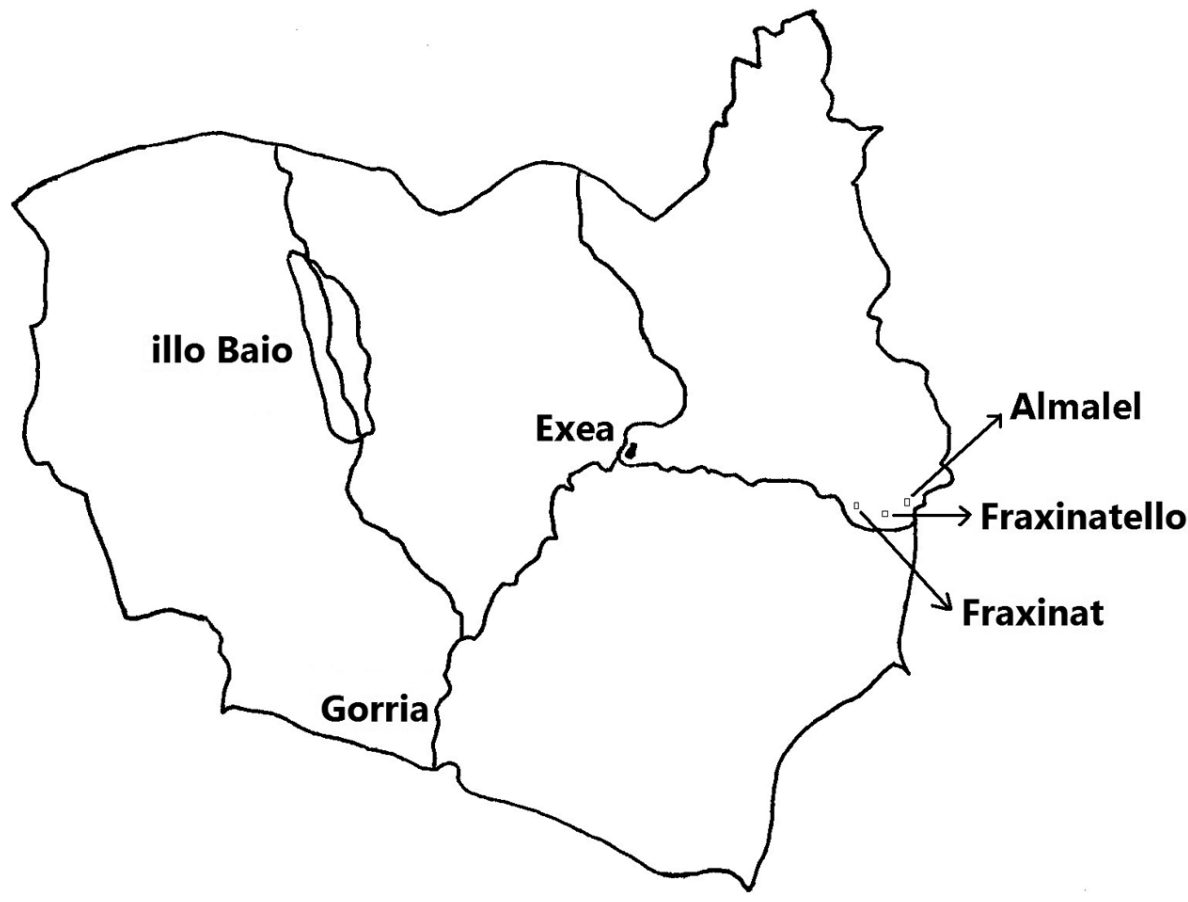

Mapa 3. Topónimos interiores mencionados en la Carta de Población de 1110.

11.- Así consta, por ejemplo, en Agustín Ubieto Arteta, Toponimia aragonesa medieval, Valencia, Anubar, 1972, p. 103. Así también en A.I. LAPEÑA \& M. ${ }^{a}$ M. Agudo, El fuero de Ejea de los Caballeros, ob. cit., p. 44 y en M. ${ }^{a}$ M. Agudo \& A. I. LAPEÑa (eds.), Joyas del Patrimonio, ob. cit., p. 38, si bien en este segundo trabajo se ofrecen reticencias a esta localización ("Gorria que podría ser la actual Gurrea del Gállego, aunque queda algo alejada del resto de los lugares”, p. 38). 
En resumen, los topónimos citados en la Carta de Población se distribuyen de la siguiente manera:

a) Ocho topónimos sirven para delimitar el perímetro del término municipal.

b) Seis topónimos tienen como elemento nuclear el apelativo torre (torr); de este número debemos descontar el topónimo Torr de Sentia, cuya explicación se efectúa en el primer bloque y que, a los efectos de nuestro análisis, computa como un solo topónimo.

c) Cinco topónimos corresponden a enclaves situados en el interior del término municipal junto a las riberas de los ríos Arba de Biel (Fraxinat, Fraxinatiello y Almalel), Riguel (illo Baio) y Arba (Gorria).

En definitiva, nuestro corpus de análisis se compone en total de dieciocho topónimos. Esta misma clasificación nos va a permitir estructurar el análisis y configurar los siguientes apartados del trabajo. El análisis individualizado de los topónimos sigue el orden en el que aparecen mencionados en el documento, y no el orden alfabético.

\section{TOPÓNIMOS DE PERÍMETRO}

\section{Barchaona}

El topónimo Barchaona se corresponde en la actualidad con el topónimo de Tauste Barcabona o Valcabona ${ }^{12}$. El lugar está situado junto al río Arba en el límite territorial entre Ejea de los Caballeros y Tauste. Barcabona se asocia fundamentalmente con la venta situada en la actual carretera A-127 GallurSangüesa en donde antaño se hacía el cambio de postas. Como venta aparece citada en el Diccionario geográfico, estadístico e histórico de Pascual Madoz (1848) y también en la relación de pueblos y despoblados de Agustín Ubieto ${ }^{13}$.

Nos encontramos ante un topónimo prelatino en el que se identifican dos formantes. El primero de ellos es la base léxica *barc-, que está presente

12.- A partir del apéndice toponímico que recoge Chusé Inazio NABARRo en su ponencia «El aragonés residual en Tauste», Tauste en su historia. Actas de las III Jornadas sobre la Historia de Tauste (Diciembre de 2001), Patronato de la Casa de Cultura \& Ayuntamiento de la Villa de Tauste, Zaragoza, 45-102. Barcabona en p. 93; Valcabona en p. 98

13.- Pascual Madoz, Diccionario geográfico, estadístico e histórico de España (1848), cito a partir de «Las Cinco Villas en el Diccionario geográfico, estadístico e histórico de España de don Pascual Madoz (1848)», Suessetania, n 8 (diciembre de 1985), pp. 5-47 (el topónimo en p. 41). Antonio Ubieto Arteta, Historia de Aragón. Los pueblos y los despoblados, tres volúmenes, Zaragoza, Anubar, 1984-1986 (el topónimo en vol. III, p.1238). 
en un gran número de topónimos peninsulares (cfr. Barca en Soria, Soto del Barco en Asturias, El Barco de Ávila en esta misma provincia, Barcarrota en Badajoz) y que a menudo ha sido objeto de la etimología popular. De controvertida adscripción lingüística ${ }^{14}$, la raíz $*$ barc- encierra la noción semántica de 'valle, hondonada'. El segundo formante del topónimo es el sufijo igualmente prelatino -ona que aparece en la formación de numerosos topónimos de origen prerromano (cfr. Argentona, Escalona, Carmona, Tarragona, Barcelona $<$ Barcinona).

Desde el punto de vista semántico, el topónimo Barchaona alude al valle, depresión o fondo del río que dibuja el río Arba a su paso por el lugar.

Los resultados actuales del topónimo se explican bien por la adición de una consonante antihiática habitual en aragonés (Barcabona), o bien por su asimilación a la copiosa serie toponímica compuesta por el apelativo val (Valcabona).

\section{Castillon de Baldiassa}

El topónimo se corresponde con el actual municipio de Castejón de Valdejasa.

Como hemos expuesto en otro lugar ${ }^{15}$, el topónimo es un compuesto cuyo elemento nuclear (castillon > castejón, del latín vulgar CASTELLIōNEM 'castillo pequeño') revela su naturaleza defensiva.

El término preposicional resulta de la aglutinación del sintagma val de Iassa, en donde encontramos el apelativo val (del latín VALLEM), la preposición de y el antropónimo latino IAssa ${ }^{16}$ : literalmente, la 'val de Iassa', en

14.- Para Álvaro Galmés de Fuentes, Los topónimos: sus blasones y trofeos (La toponimia mítica), Madrid, Real Academia de la Historia, 2000, p. 38, se trata de la raíz ibérica *ib- con el significado de 'río', y el sufijo denominativo - $k a-,-k o-$, que da como resultado formas del tipo (i)bar-ka, (i) bar-ko, con pérdida temprana de $i$ - inicial; para Franciso Villar LiÉBANA, la raíz es compatible con la indoeuropeidad a partir de la raíz *war- 'agua, río, corriente', con sufijo primario -ko- sin vocal presufijal (en Lenguas, genes y culturas en la Prehistoria de Europa y Asia suroccidental, Salamanca, Universidad de Salamanca, Acta Salmanticensia, 2011, p. 642; vid. la distribución geográfica de esta serie y sus variantes formales en pp. 301-304; en este mismo estudio, concretamente en pp. 486-493, se revisa la adscrición ibérica de $* i b$-).

15.- Marcelino Cortés Valenciano, Toponimia de las Cinco Villas de Aragón, Centro de Estudios de las Cinco Villas de la Institución «Fernando el Católico» \& Ayuntamiento de Ejea de los Caballeros, 2010, pp.108-110. En estas páginas se someten a consideración otras hipótesis explicativas relacionadas con el topónimo.

16.- Barbanás LöRINCZ, Onomastique Provinciarum Europae Latinarum. Ex materia ab A. Mócsy, R. Feldmann, E. Marton et M. Szilágyi collecta composuit et correxit Barbanás LÖRINCZ, cuatro volúmenes, Wien, Forschungsgesellschaft Wiener Stadtarchäologie, 2000, vol. III, p. 190, como cognomen; IASsus en Heikki Solin \& Olli Salomies, Repertorium hominum gentilium et cognominum Latinorum, Hildesheim, Olms-Weidmann, 1988, p. 95, dentro de los gentilicia. 
referencia al propietario o poseedor del lugar así nombrado, reproduciéndose la habitual estructura sintagmática romance utilizada para la expresión de la propiedad (nombre común + preposición de + nombre del poseedor).

\section{Sentia}

El topónimo Sentia se conserva en la actualidad como Santia y se sitúa entre los límites fronterizos de Ejea y Erla en terreno de regadío tradicional junto al río Arba de Biel. En el lugar se emplaza el torreón medieval de Santia que ha dado lugar a la Torr de Sentia también citada el documento que estudiamos.

El topónimo Sentia tiene su origen en un nombre personal referido al propietario o poseedor del terreno; en este caso, se trata del cognomen latino SENTIA ${ }^{17}$.

El resultado actual del topónimo ofrece un cambio de timbre de la vocal tónica (Sentia $>$ Santia) que posiblemente se deba a una atracción paronímica encaminada a asimilar el primitivo nombre Sentia con los habituales hagiotopónimos encabezados por el adjetivo apocopado san (del latín SANCTUS) ${ }^{18}$.

\section{Fraxino de rio de Ores}

El topónimo carece de correlato en la actualidad.

Su localización remite a uno de los afluentes del río Arba de Luesia: concretamente a las aguas que discurren bajo el núcleo urbano de Orés — de donde el cauce toma su denominación - y afluyen al río Arba de Luesia a través del Barranco de Ejea de los Caballeros, tal y como es nombrado en la cartografía oficial ${ }^{19}$.

El topónimo deriva del nombre común latino FRAXINU 'fresno', especie arbórea frecuente en las zonas ribereñas de los ríos. A diferencia de lo que en el siguiente apartado del estudio veremos, lo que motiva el topónimo no es una masa arbórea de fresnos, sino precisamente su singularidad en el paisaje.

El apelativo fraxino, voz propiamente aragonesa, completa su significación con un señalizador de orientación: literalmente, 'el fresno del río que viene

17.- Ibídem, p. 167.

18.- En todo caso, el cambio Sentia > Santia lo podemos fechar en época moderna. En un documento fechado el 26 de junio de 1400 todavía aparece la forma original: et de Sancha Ferrandez de Sentia (Archivo Parroquial de Ejea de los Caballeros [APE de aquí en adelante], sin signatura; José Ramón Auría Labayen, Documentación medieval del Archivo Parroquial de Ejea de los Caballeros: transcripción, tesis de licenciatura inédita, 1982 [DAPE de aquí en adelante], doc. 107).

19.- Instituto Geográfico y Catastral, hoja no 284, Ejea de los Caballeros, ediciones de 1932 y 1953. 
de Orés'. Compárese este mismo procedimiento en la denominación de los dos brazos del río Arba: Arba de Luesia y Arba de Biel.

\section{Fraxino de rio de Aonna}

El topónimo carece de correlato en la actualidad.

La mayor parte de las informaciones aportadas en la entrada anterior son válidas para illo Fraxino de rio de Aonna: el fitónimo fraxino (> fresno) precisa su noción espacial con un hidrónimo: literalmente, 'el fresno del río Aonna'. El rio de Aonna se corresponde con el río Agonías (o Agonias), río que comparte nomenclatura oficial con la denominación río Farasdués, siendo ésta última la denominación más usada en la actualidad ${ }^{20}$.

El topónimo se localiza al norte del municipio, en el límite de Ejea de los Caballeros con el antiguo municipio de Farasdués.

\section{Arripa Roia}

El topónimo Arripa Roia o Ripa Roia carece de vigencia apelativa en la actualidad. Sólo la documentación medieval nos permite fijar con exactitud el emplazamiento.

En un documento del año 1300 por el que se obliga a Biota a restituir el agua del río Arba de Luesia a Ejea en el marco de los pleitos y disputas que ambos municipios sostuvieron durante siglos por dicha cuestión, leemos: et otro açud que es clamada de Ripa Roya ${ }^{21}$. De este pasaje se desprende que Ripa Roia se localizaba en los límites territoriales entre Ejea y Biota, en el lugar en donde las aguas del río Arba de Luesia dejan el término municipal de Biota y entran en el de Ejea de los Caballeros.

Del latín RĪPAM 'margen del río, orilla, ribera' y del adjetivo latino RUBĚAM 'roja'.

20.- Sobre el hidrónimo Aonna, su etimología y los cambios que explican el resultado actual a través de la llamada etimología popular (Agonías), vid. Marcelino Cortés Valenciano, Toponimia de Ejea de los Caballeros, Zaragoza, Institución «Fernando el Católico» \& Ayuntamiento de Ejea de los Caballeros, 2005, pp. 43-44.

21.- AHME, doc. A.1.4. (29 de septiembre de 1300). El documento fue reproducido por Elena PIEDRAFITA PÉreZ en su artículo «Relaciones entre los concejos cincovilleses en los siglos XIII y XIV: conflictos y solidaridades», Suessetania, $\mathrm{n}^{\circ} 13$ (1993), pp. 96-119. Figura como Documento n 3 en pp. 114-116. La regesta del documento es la siguiente: "Martín de Borau, lugarteniente del sobrejuntero de Ejea, comunica al consejo de Biota la orden real referente a la restitución al concejo de Ejea del agua del Arba. Seguidamente dicho oficial y el zavacequia de Ejea inspeccionan personalmente las propiedades de los de Biota y destruyen los azudes que obstaculizan el libre paso del agua hacia Ejea" (ibídem). 
Desde el punto de vista del significado, se aprecian dos nociones semánticas. Por un lado, el sustantivo RĪPAM alude al emplazamiento de un lugar circundante al curso de un río. Por otro lado, el adjetivo RUB̌̌Am aporta una noción cromática rojiza motivada por una determinada realidad física del terreno nombrado, generalmente terrenos arcillosos: 'ribera roja'.

Formalmente, en el sustantivo todavía no se ha producido la sonorización de - $p$ - intervocálica (RĪPAM > riva, riba) y se observa la habitual alternancia de formas con vocal y formas sin vocal protética $a$ - cuando la palabra comienza por la vibrante múltiple (Arripa / Ripa). En el caso del adjetivo RUBĚAM encontramos la solución típicamente aragonesa del grupo latino -BY- (roya), frente al resultado propiamente culto (rubio).

\section{Capeza de Aquisillo}

El topónimo no tiene correlato con un topónimo en la actualidad.

Sin embargo, su aparición frecuente y temprana en la documentación nos permite fijar con bastante precisión su localización entre Sádaba y El Bayo: la Capeza de Aquisillo se sitúa al sur de la villa de Sádaba, en el terreno en el que el río Riguel se interna en territorio de Ejea. Históricamente el lugar de Aquisillo sirvió para delimitar el término municipal de Ejea frente a los enclaves señoriales de Biota y de El Bayo.

La primera mención del topónimo data del siglo X y se encuentra en un documento en el que el rey Sancho Garcés I señala los términos de Uncastillo (Aquisilio) ${ }^{22}$. En 1095 el rey Pedro I concede la almunia de Aguisillo a Santa María de Pamplona y al obispo don Pedro Zubiría ${ }^{23}$. En 1155 Aquisillo formará parte de una donación del Consejo de Uncastillo a la iglesia de Santa María de esta villa ${ }^{24}$.

La primera parte del topónimo deriva del latín CAPĪTIA 'cabeza, cabo', en referencia a una posición elevada del terreno en clara metáfora oronímica, si bien en el ámbito lingüístico aragonés es más frecuente el apelativo cabezo procedente de la forma masculina CAPĪTIUM.

22.- Antonio Ubieto Arteta (ed.), Documentos reales navarro-aragoneses hasta el año 1004, Zaragoza, Anubar, Textos Medievales, 1986, doc. 16, años 905-925: usque ad capeza de Aquisilio vetulo. Documento calificado por A. UвIETo como "sospechoso".

23.- Antonio Ubieto Arteta (ed.), Colección diplomática de Pedro I de Aragón y Navarra, Zaragoza, Escuela de Estudios Medievales, Consejo Superior de Investigaciones Científicas, 1951, doc. 19, octubre de 1095: et concedo unam meam almuniam que vocatur Aguisillio cum omni suo termino.

24.- Ref. Elena Piedrafita Pérez, Las Cinco Villas en la Edad Media (siglos XI-XIII). Sistemas de repoblación y ocupación del espacio, Zaragoza, Institución «Fernando el Católico», 2000, p. 141. 
El término preposicional nos remite al topónimo Aquisillo, nombre de lugar que presenta en la documentación medieval una gran variabilidad formal (Aquisilio, Aguisillio, Aquisillo, Axilio, Aqsilio, Acsillo, Asiello y Axillo) ${ }^{25}$.

Esta variabilidad formal tiene su origen en las distintas formas que adopta el antropónimo latino del que deriva: Axilius, Axillius, Axsilliuss ${ }^{26}$.

En todo caso, nos encontramos ante la denominación de una antigua villa o hacienda hispano-romana, nombrada, como es habitual, a partir del nombre personal de su propietario.

\section{Bardena}

El topónimo illa Bardena clausura la enumeración del perímetro territorial de Ejea de los Caballeros, comprendiendo todo el territorio occidental del municipio.

La etimología del topónimo Bardena ha estado sujeta a distintas interpretaciones $^{27}$. No obstante, conviene advertir que, como señala J. A. Frago, la voz bardena tenía todavía en la Edad Media "función apelativa, con significados próximos a los de pastizal, monte comunal, si bien hoy es un término meramente toponímico"28. En la actualidad prácticamente no hay municipio de las Cinco Villas zaragozanas que no cuente con el topónimo Bardena en su repertorio toponomástico.

Nótese, por último, cómo el topónimo aparece ya en 1110 en singular (illa Bardena) frente al plural Las Bardenas, y lo hace acompañado del artículo femenino (illa).

\section{TOPÓNIMOS DEFENSIVOS: LAS TORRES}

La Carta de Población de Ejea de los Caballeros contiene seis topónimos formados sobre el apelativo Torr / Tor, resultado apocopado del sustantivo latino TŬRREM 'torre'.

25.- Sobre todas estas cuestiones remitimos a M. CoRTÉs, Toponimia de las Cinco Villas, ob. cit., pp. 91-92, en donde nos ocupamos de manera monográfica del topónimo (v. Axillo).

26.- Axilius en H. Solin \& O. Salomies, ob. cit., p. 30, dentro de los gentilicia, y Axillius también como cognomen (ibídem, p. 299); Axillius, Axsillius en B. Lörincz, ob. cit., vol. I, p. 106, nomen.

27.- Para un análisis pormenorizado de la cuestión remitimos a nuestro trabajo M. Cortés, Toponimia de Ejea de los Caballeros, ob. cit., pp. 50-51.

28.- Juan Antonio Frago Gracia, «Toponimia navarroaragonesa del Ebro (V): Yermos y pastizales», Archivo de Filología Aragonesa, XXXVIII (1986), pp. 89-119. La cita en p. 95. 
El significado es transparente y designa un elemento arquitectónico de carácter militar. Sin embargo, es necesario advertir que en los documentos navarro-aragoneses la voz torre tuvo ya desde el siglo XII el significado de 'casa de campo, alquería' ${ }^{29}$. Se trata, lógicamente, de un proceso metonímico por el que el apelativo torre, una vez perdida su función defensiva primitiva, extendió su campo significativo hasta alcanzar el conjunto del hábitat rural (personas y tierras) al que daba protección.

Expuestas las consideraciones anteriores, que son comunes para este grupo de topónimos, nos detendremos en el análisis del resto de modificadores, exceptuando la Torr de Sentia, para cuya explicación remitimos al análisis efectuado en el apartado anterior (vid. Sentia).

\section{Torr de Escoron}

La Torr de Escoron se corresponde con el actual término de Escorón. Se trata de una de las vegas tradicionales de Ejea, próxima ya a los límites de Tauste. Dentro de esta línea de fortificaciones medievales recogidas en la Carta de Población la Torr de Escoron era el enclave situado más al sur. En la actualidad se conservan los restos de la base de esta torre defensiva sobre un cerro testigo situado en la margen derecha del río $\mathrm{Arba}^{30}$.

A diferencia de lo que hemos sostenido anteriormente ${ }^{31}$, el topónimo Escorón se explica a partir del cognomen SCAURUS ${ }^{32}$, derivado por medio del sufijo -O/NIS (*SCAURONEM) ${ }^{33}$. Nos encontramos, por lo tanto, ante la denominación

29.- Juan Antonio Frago Gracia, Toponimia del Campo de Borja. Estudio lexicológico, Zaragoza, Institución «Fernando el Católico», Temas aragoneses, 1980, p. 185. Sobre la cuestión remito al trabajo de Antonio Ubieto Arteta, «El topónimo Torre / Torres en Aragón», Homenaje al profesor Juan Torres Fontes, dos vols., Murcia, Universidad de Murcia, tomo II, pp. 1681-1687. En p. 1682 se ofrece una definición completa del apelativo torre en el Valle del Ebro. Ninguna de las torres que se mencionan en la Carta de Población se incluye en la relación de 109 torres propuestas por A. Ubieto en una cronología que va del año 707 a 1286.

30.- Sobre los restos arqueológicos hallados en el lugar de Escorón y otras informaciones complementarias referidas a este enclave, vid. el trabajo de Carmen MARín JARAUTA, «San Gaudioso, un santo ejeano», Suessetania, 23 (2007), pp. 142-158.

31.- M. Contés, Toponimia de las Cinco Villas, ob. cit., pp. 123-124. En este trabajo postulábamos una interpretación motivada por el pronunciado meandro que traza el río Arba en la zona, adoptando una posición casi perpendicular a la dirección del cauce, en una zona en donde frecuentemente se depositan materiales de arrastres del río (del latín scōRIA 'escoria', en el sentido de 'restos y materiales que dejan los aluviones en el cauce del río', y sufijo -ón, del latín -ōNEM).

32.- B. Lörincz, ob. cit, vol. Iv, p. 54; H. Solin \& O. SAlomies, ob. cit., p. 398; Iiro KaJanto, The Latin Cognomina, Roma, Giorgio Bretschneider Editore, 1982, p. 242 (Cognomina relating to human body and mind. III. Physical peculiarities, pejorative names.3.Other parts of the body). Otros derivados del cognomen son ScaurinUs (con el sufijo -INUS/NA) o SCAURIANUs (con el sufijo -IANUS/NA).

33.- Sobre el sufijo -o/NIS, vid. I. KaJAnTo, ob. cit., p. 118. 
de una antigua villa o hacienda hispano-romana, revelada a través del nombre personal de su propietario o poseedor.

Como información complementaria al topónimo, queremos señalar que la primera mención documental de Escorón es la que aparece precisamente en este documento de julio de 1110. José María Lacarra anotó por error el topónimo Escorón en un documento fechado en enero de 1091: Senior Galindo Date in Escoron ${ }^{34}$. Ángel Canellas, por su parte, recoge este mismo pasaje del documento de esta manera: senior Galin Dat en Escorun ${ }^{35}$. Aunque en el índice toponímico de este último repertorio figura como entrada propia Escorún, tanto el personaje como el contexto del citado documento remiten al actual despoblado de Secorún (Boltaña, Huesca), y no al lugar de Escorón.

\section{Torr de Canals}

La Torr de Canals se corresponde con el topónimo actual de Las Canales, nombre que recibe una de las vegas tradicionales situadas en la margen izquierda del río Arba. En el lugar se encuentra también el microtopónimo Estanca de Canales.

Del latín CANALEM 'canal', en alusión al sistema de riegos existentes desde antiguo en toda la llanura que surca el río Arba entre Ejea y Tauste.

El apelativo canal es una voz desacostumbrada en el léxico del riego de la zona y su uso actual siempre está referido a las modernas infraestructuras de regadío (cfr. el Canal de las Bardenas). La voz tradicional para designar los cauces que conducen el agua hasta el terreno a inundar siempre ha sido acequia (o sus variantes en el habla cequia, ceica o zaica) ${ }^{36}$, huella evidente del mundo musulmán en todo lo relativo al uso del agua. Sin embargo, la palabra canal aparece con bastante frecuencia en toponimia para designar cualquier curso pequeño de agua ${ }^{37}$.

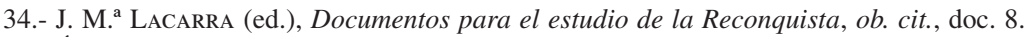

35.- Ángel Canellas López (ed.), Colección diplomática de Sancho Ramírez, Zaragoza, Real Sociedad Económica de Amigos del País, CAI-100, 1993, doc. 24.

36.- Rosa M. ${ }^{a}$ CASTAÑer Martín, en su estudio Forma y estructura del riego en Aragón, Navarra y Rioja, Zaragoza, Institución «Fernando el Católico», 1983, señala a propósito de la voz canal: "Esta voz no está muy extendida en la región" (p. 14).

37.- Vid. Jesús VÁzquez Obrador, «Toponimia de Sobremonte (Huesca), II: Hidronimia», Homenaje a «Amigos de Serrablo», Huesca, Instituto de Estudios Altoaragoneses, 1989, pp. 421-450; en concreto, p. 427; y también William Dennis Elcock, «Amigos de Serrablo», Archivo de Filología Aragonesa, 12-13 (1961-62), pp. 229-320, especialmente en p. 309. 


\section{Torr de Annessa}

La Torr de Annessa se corresponde en la actualidad con Añesa, topónimo con el que se nombra una de las vegas tradicionales y más renombradas de Ejea de los Caballeros, situada en la margen derecha del río Arba.

La primera mención documental se encuentra en el documento que analizamos y en ella Annessa aparece como una de las torres defensivas. Apenas siete años después, cuando en marzo de 1117 el rey Alfonso I concede el lugar a Lope Garcés Peregrino, se la denomina pardina de Anniessia ${ }^{38}$. Después de varias donaciones, la almunia de Anniesse, como se la nombra en $1147^{39}$, pasará a ser propiedad de la Orden del Temple ${ }^{40}$.

El topónimo Añesa tiene su origen en el antropónimo AnNIUs ${ }^{41}$ derivado por medio del sufijo -ĚSsA. La marca de género nos permite reconstruir el tradicional sintagma empleado para la expresión de la propiedad: VILLA AnNiessa, es decir, 'la villa de Annio'. Nos encontramos, por tanto, ante la denominación de una antigua hacienda o villa nombrada, como es habitual, a partir del nombre de su propietario. Las prospecciones arqueológicas han determinado la existencia en el lugar de restos de una antigua villa romana sin una cronología exacta ${ }^{42}$.

En lo que respecta a la sufijación, Gerhard Rohlfs estableció que -Ěssa, -ĚSSU son meras variantes del sufijo -ŏssu. Asimismo, este autor señaló cómo este sufijo -ŏssu sirvió tanto para la formación de nombres de persona como nombres de dominios, siendo un sufijo que tenía la misma función que el sufijo galo -ACOS o el sufijo romano -ANUS, aunque no lo atribuyó a ningún grupo étnico concreto ${ }^{43}$.

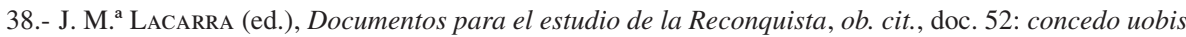
illa pardina de Anniessia cum suo termino.

39.- Ibídem, doc. 34: dono et concedo illa almunia de Anniesse omnia.

40.- Sobre la evolución histórica de este enclave véase el estudio de Santiago CAPUd AguAdé, «Añesa. Una encomienda templaria en las Cinco Villas», Suessetania, n 14 (1994-95), pp. 21-31. Vid. también el trabajo de E. Piedrafita, Las Cinco Villas en la Edad Media, ob. cit., pp. 167-168.

41.- H. Solin \& O. Salomies, ob. cit., p. 16; B. LöRIncZ, ob. cit., vol. I, pp. 56-57.

42.- Vid. M. ${ }^{a}$ de la Peña Lanzarote Subías (coord.), El patrimonio artístico de la comarca de las Cinco Villas, Ejea de los Caballeros, Centro de Estudios de las Cinco Villas \& Institución «Fernando el Católico», 1998, p. 19.

43.- Gerhard Rohlfs, Studien zur romanischen Namenkunde, München, Bayerische Academie der Wissenchaften, 1956, p. 116. Este sufijo y su extensión en la toponimia de las Cinco Villas de Aragón han sido objeto de un trabajo específico por nuestra parte: Marcelino Cortés VAlenciano, «Los topónimos terminados en -ués, -és, -iés en las Cinco Villas de Aragón», Archivo de Filología Aragonesa, $\mathrm{n}^{\circ} 66$ (2010), pp. 281-303. 
MARCELINO CORTÉS VALENCIANO

\section{Torr Longa} lidad.

El topónimo Torr Longa carece de correlato toponímico en la actua-

Por otra parte, la presencia de este topónimo es escasa en las fuentes documentales. Elena Piedrafita recoge la mención en 1212 de las canals de la Torre Longa en un pleito por el uso de las acequias en la zona de Añesa ${ }^{44}$. En el Archivo Parroquial de Ejea de los Caballeros sólo aparece mencionado en una sola ocasión, en un testamento fechado a principios del siglo XV, siendo la última mención documental que hemos encontrado (Todaluenga) ${ }^{45}$.

Su localización hasta la fecha se situaba de modo genérico en el entorno de Añesa. Los escasos datos históricos disponibles, así como el orden enumerativo del propio documento así lo apuntaban.

Sin embargo, desde el 2009 la localización precisa de la Torr Longa ha sido posible gracias a un nuevo yacimiento localizado por el arqueólogo Juan José Bienes Calvo en la partida de Abejares. La noticia de dicho yacimiento se recoge en el ApÉnDICE II ("Estudio arqueológico de los yacimientos") de la monografía de Isaac Moreno Gallo titulada Item a Caesarea Augusta Beneharno $^{46}$.

Según se puede inferir de los datos recogidos en este apéndice, la Torr Longa se emplazaba en la corona de un cerro testigo que está situado a escasos 75 metros de la actual carretera A-127 Gallur-Sangüesa. Como señala J.J. Bienes, "la parte alta del cerro es amesetada, hallándose los restos de una edificación muy arrasada. Tiene planta rectangular, casi imperceptible, con unas dimensiones de 11 x 5,5 m. [...] Como elementos curiosos tiene, en la zona Norte, posiblemente la de la entrada, unas estructuras de forma cuadrangular, incompletas, realizadas en piedra arenisca, con ángulos tallados. La cronología de este edificio es medieval"47.

44.- Archivo Histórico Nacional, Cartulario de Castiliscar, Órdenes Militares, carpeta 655, doc. 13 y 15 , B: Et si forte illas canals d'Ascesallar per las canals de la Torre Longa. Cito a partir de Elena PIEDRAFITA PÉREZ, La organización territorial y la propiedad de la tierra en las Cinco Villas durante los siglos XII y XIII, cuatro volúmenes, tesis doctoral, Universidad de Zaragoza; la cita en Colección documental, tomo I, doc. 302, p. 258. Estos mismos datos son recogidos también por M. ${ }^{\mathrm{a}} \mathrm{M}$. AGUDO \& A.I. LAPEÑA (eds.), Joyas del Patrimonio, ob. cit., p. 38.

45.- APE, sin signatura; DAPE, doc. 110, 30 de marzo de 1405: un campo sitiado en Todaluenga, termino de la dita villa.

46.- Isaac Moreno Gallo, Item a Caesarea Augusta Beneharno. La carretera romana de Zaragoza al Bearn, Ejea de los Caballeros, Centro de Estudios de las Cinco Villas \& Institución «Fernando el Católico», 2009. El apéndice en pp. 241-261; la descripción completa del yacimiento localizado en la partida de Abejares en p. 247.

47.- Ibídem. En este yacimiento se encontraron también "restos de diferentes cronologías. Las cerámicas de época romana se encuentran en la ladera sur, concentradas en una pequeña superficie donde abundan 
Esta planta rectangular de la torre es la que originó el topónimo Torr Longa. A diferencia de las torres anteriores, en donde el apelativo torre precisaba su localización mediante un topónimo preexistente (Escoron, Canals, Annesa), la referencia deíctica de esta torre se basó en la morfología del edificio defensivo mediante el calificativo longa (del latín LŎNGUS, -A, -UM 'largo'), adjetivo que fue muy frecuente durante toda la Edad Media, pero que cayó en desuso a partir del siglo XV, siendo sustituido por el adjetivo largo (del latín LARGUS, -A, -UM) ${ }^{48}$.

El caso de Torr Longa es un ejemplo elocuente de cómo un topónimo es sustituido por otro (retoponimización). Perdida la noción espacial que motivaba el topónimo - la torre alargada, cuyas piedras seguramente serían reutilizadas para otros usos en virtud de la economía de la piedra practicada desde antiguo en la zona —, el hablante lo reemplazó por otra actividad — la apicultura- que comenzó a desarrollarse en el entorno de ese cerro y terminó por darle otro nombre: Abejares.

\section{Torr de Arripas}

Situada en la margen izquierda del río Arba de Luesia, la Torr de Arripas se corresponde con Rivas, barrio tradicional de Ejea de los Caballeros, de cuyo núcleo urbano dista cuatro kilómetros. En este dispositivo defensivo revelado por la Carta de Población la Torr de Arripas es la torre más septentrional.

Del latín RĪPAS 'márgenes del río, orillas, riberas'. Se trata de un topónimo que señala el emplazamiento de un lugar circundante al curso de un río.

Con respecto a los aspectos lingüísticos del topónimo, véase lo comentado en la entrada correspondiente a Arripa Roia.

\section{TOPÓNIMOS INTERIORES}

\section{Fraxinat}

El topónimo Fraxinat, Fraxinet se corresponde en la actualidad con Los Frajinetes o, como figura en la nomenclatura oficial y en la cartografía, Los Fajinetes. El lugar se localiza al este del municipio, en una terraza fluvial junto al río Arba de Biel, próxima al término municipal de Luna.

trozos pequeños de piedra caliza. Se recogen diminutos fragmentos de cerámicas de mesa y comunes, con una cronología de Época Imperial Romana S. I-II d.C." (ibídem).

48.- Joan Corominas en colaboración con José Antonio Pascual, Diccionario crítico etimológico castellano e hispánico, 6 volúmenes, Madrid, Gredos, 1980-1991, v. largo. 
El topónimo aparece atestiguado por primera vez en 1092 en un documento por el que el rey Sancho Ramírez concede al Monasterio de San Juan de la Peña las décimas de Luna y de varias almunias próximas a esta villa, entre las que se encuentra Frasseneto ${ }^{49}$. Siete años más tarde, el topónimo vuelve a ser citado en un documento por el que el rey Pedro I concede a San Juan de la Peña la capilla real de Luna dedicada a San Nicolás con todas sus pertenencias $(\text { Fraxeneto })^{50}$. A finales del siglo XVI el topónimo mantenía su estructura fonética intacta (Fraxinet $)^{51}$.

El topónimo tiene como base léxica el nombre común latino FRAXINU 'fresno', derivado mediante el sufijo locativo-abundancial -ĒTUM ( $>$-edo), característico de los fitónimos ${ }^{52}$. Significado transparente: 'fresneda, lugar en donde abundan los fresnos'.

El topónimo Fraxinet se ha conservado prácticamente igual a la forma latina, ya que en el habla es frecuente oírlo como Los Frajinetes. La única modificación ha sido la adición redundante de la marca de plural en un sustantivo colectivo. La otra forma que actualmente se registra del topónimo es la de Los Fajinetes, forma motivada por la similitud del sustantivo fajina, del latín FASCIA 'haza, faja, hacina, gavilla', con sufijo -ina, de gran uso en el ámbito ganadero y agrícola de la zona.

\section{Fraxinitiello}

Por cuestiones documentales, geográficas y lingüísticas debemos vincular el análisis de este topónimo con el topónimo anterior Fraxinet.

Fraxinitiello no tiene un correlato toponímico actual y, a falta de restos arqueológicos, no podemos dar una ubicación precisa. Sin embargo, todas las referencias nos llevan a localizar el topónimo en una zona ribereña del río Arba de Biel en el límite con la villa de Luna, en una zona muy próxima a Fraxinet (Los Fajinetes).

La aparición documental de Fraxinitiello está ligada a los mismos documentos que el topónimo anterior. Se atestigua por primera vez en septiembre

49.- José Salarrullana de Dios (ed.), Documentos correspondientes al reinado de Sancho Ramírez. Desde MLXIII hasta MLXXXXIIII años, vol. I, Zaragoza, M. Escar, 1907, doc. XLVII, 4 de septiembre de 1092: illas almunias de Libros, de Erlla [...], de Frasseneto.

50.- Antonio Ubieto (ed.), Colección diplomática de Pedro I, ob.cit., doc. 66: de illas almunias quas dedi per alodem Fraxeneto de super.

51.- AHME, B.38.52, año 1593: y el monte llamado fraxinet.

52.- Sobre este sufijo, vid. David Pharies, Diccionario etimológico de los sufijos españoles y de otros elementos finales, Madrid, Gredos, Biblioteca Románica Hispánica, 2002, pp. 192-193, v. -edo. 


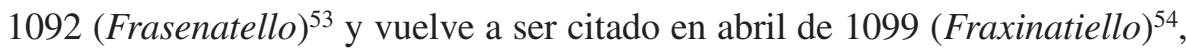
nombrándose en ambos casos como almunia. En la Historia de la economía política de Aragón (1798) de Ignacio Jordán de Asso se cita conjuntamente con el anterior como despoblados: "Fraxineto y Fraxinetiello cerca de Luna" 55.

Etimológicamente, Fraxinetiello es la forma diminutiva de Fraxinet, derivada mediante el sufijo - $\breve{L L U}(>- \text { iello })^{56}$ : literalmente, 'fresnedilla, fresneda pequeña'. Es, pues, un fitotopónimo que concuerda plenamente con las referencias corográficas en donde se localiza.

\section{Almalel}

El topónimo Almalel no se corresponde en la actualidad con ningún topónimo.

El lugar estaba situado al este del municipio de Ejea de los Caballeros sobre una terraza fluvial del río Arba de Biel próxima al límite territorial de la villa de Luna.

La primera mención del topónimo (Almalel) procede del ya citado documento de 1092 por el que el rey Sancho Ramírez concede al Monasterio de San Juan de la Peña las décimas de varias almunias cercanas a Luna ${ }^{57}$. La vigencia apelativa del topónimo la hemos podido constatar hasta el siglo XV $(\text { Almaler })^{58}$. En 1789 el ilustrado Ignacio Jordán de Asso lo cita en la relación de despoblados que recoge en la Historia de la economía política de Aragón: "Almalel, lugar poco distante de Luna"59.

Como me apunta el profesor Federico Corriente Córdoba ${ }^{60}$, es bastante probable que Almalel sea una voz árabe hibridada con un sufijo romance, -el

53.- J. Salarrullana (ed.), Documentos correspondientes al reinado de Sancho Ramírez, ob. cit., doc. XLVII, 4 de septiembre de 1092: illas almunias de Libros, de Erlla [...] et Frasenatello.

54.- Antonio Ubieto (ed.), Colección diplomática de Pedro I, ob.cit., doc. 66: et Fraxinatiello de iuso cum omnibus directaticiis.

55.- Ignacio Jordán De Asso, Historia de la economía política de Aragón (1789), cito a partir de «Las Cinco Villas en la Historia de la economía política de Aragón de don Ignacio de Asso. Un documento para el debate», Suessetania, ${ }^{\circ} 5$ (abril de 1984), pp. 18-23. La cita en p. 23.

56.- Sobre este sufijo, vid. D. Pharies, ob. cit., pp. 326-329, v. -illo.

57.- J. Salarrullana (ed.), Documentos correspondientes al reinado de Sancho Ramírez, ob. cit., doc. XLVII, 4 de septiembre de 1092: illas almunias de Libros, de Erlla [...], de Almalel.

58.- AHME, A.1.6, 4 de enero de 1421: las partidas de Almaler y de la sierra.

59.- Cito a partir de «Las Cinco Villas en la Historia de la economía política de Aragón de don Ignacio de Asso. Un documento para el debate», Suessetania, n 5 (abril de 1984), pp. 18-23. La cita en p. 23.

60.- Explicación transmitida en respuesta a una consulta ad hoc formulada por el autor de estas líneas y que está incluida en el análisis que del topónimo realizamos en M. CoRTÉs, Toponimia de las Cinco Villas, ob. cit., pp. 84-85, en donde nos detenemos en precisar más en detalle los aspectos morfofonéticos del topónimo. Desde estas líneas agradecemos nuevamente al profesor Federico Corriente Córdoba su amable atención y sus conocimientos. 
o -er, quedando una base léxica mal- que puede tener muchas equivalencias árabes.

La hipótesis más razonable desde el punto de vista corográfico tiene como base la voz árabe mar'a 'dehesa, pasto', con la sufijación romance arriba señalada.

\section{Gorria}

Como ya hemos avanzado en el tercer apartado del estudio, Gorria es un topónimo que ha dado pie a equívocos, llegando a identificarse con la localidad de Gurrea de Gállego, en la Hoya de Huesca.

Efectivamente, el topónimo Gorria es un caso muy singular y paradójico por dos motivos: en primer lugar, porque el topónimo sobrevive, aunque lo hace bajo otra denominación; en segundo lugar, porque, a contrapelo de lo que sucede en la metodología empleada en la investigación toponímica, las fuentes modernas nos proporcionan más información que las antiguas.

Tal y como se muestra en la documentación de la Edad Moderna, el topónimo Gorria se ha mantenido en el tiempo bajo la construcción El Salobrar de Gurrea. Así aparece reflejado, por ejemplo, en la Relación de los Propios y Arineros [sic] de la villa de Exea de los Caballeros, del año $1761^{61}$. El Salobrar de Gurrea fue una de las corralizas o dehesas comunales subastadas en el proceso desamortizador llevado a cabo en el año $1860^{62}$.

Todos estos datos nos ayudan a situar el lugar al sur del municipio, muy cerca de la muga con el municipio de Tauste, y en la margen derecha del río Arba. En la actualidad el topónimo ha ido perdiendo su término preposicional, quedándose únicamente el término nuclear (El Salobrar); para muchos lugareños se reduce básicamente al microtopónimo Casas del Salobrar.

61.- AHME, B.28.58, 5 de abril de 1761: Por las yerbas de las corralizas llamadas Valdecuadros y Salobrar de Gurrea. Durante toda la Edad Moderna El Salobrar de Gurrea estuvo destinada a usos ganaderos, especialmente de cabaña brava, explotada por parte de la Casa de Ganaderos de la villa de Exea de los Caballeros. Según consta en el Libro de resoluciones, actas y cuenta y erecciones del mayordomo, y apoderados del capítulo, y Casa de Ganaderos de la villa de Exea de los Caballeros, del año 1794, El Salobrar de Gurrea fue una corraliza de propios que contaba con una cavida de 300 cabezas de ganado (cito a partir de Yolanda RuIz Urbón, «Libro de resoluciones y cuentas de la Casa de Ganaderos de Ejea de los Caballeros», Suessetania, n 12 [agosto de 1992], pp. 105-124; el dato en p. 124).

62.- El Salobar de Gurrea contaba con una extensión de 140,03 hectáreas y fue adquirida en primera instancia por Sebastián Covarrubias y recomprada posteriormente por Esteban López (Fuente: Encarna Moreno Del Rincón, La desamortización en la provincia de Zaragoza, Barcelona, Universidad Autónoma, tesis doctoral, 1993, pp. 491-492). 
La etimología del topónimo Gorria dista mucho de estar clara. Pasamos a continuación a comentar brevemente las propuestas más relevantes que se han formulado al respecto, proponiendo finalmente nuestra hipótesis de interpretación.

De entrada, queda descartado poner en relación el topónimo con la voz vasca gorri 'rojo', que aparece en algunos cromotopónimos; por ejemplo, la interpretación más tradicional que se ha propuesto para Calahorra $(<$ Cala gorris, 'castillo rojo') ${ }^{63}$. El color rojizo no se corresponde con la tonalidad blanquecina de los terrenos salinos del terreno que han motivado el apelativo salobrar.

Otra vía interpretativa nos lleva a relacionar Gorria con los topónimos que forman su serie toponímica: por un lado, los topónimos del tipo Gurrea (Gurrea de Gállego, Alcalá de Gurrea); por otro, los topónimos del tipo Urrea (como Urrea de Jalón, en Zaragoza, o Urrea de Gaén, en Teruel).

Efectivamente, los topónimos Urrea / Gurrea son meras variantes formales de un mismo topónimo, siendo la primera la forma primitiva. La única diferencia estriba en que los topónimos del tipo Gurrea han desarrollado una consonante velar protética (Urrea > Gurrea), fenómeno fonético similar al que se observa en otros topónimos que comienzan con vocales velares /o/-/u/ (cfr. Orbea / Gorbea; Odiel / Gudiel).

Analizando el topónimo Gurrea de Gállego y partiendo de una forma tardía -Orreia, documentada en 1209-Álvaro Galmés de Fuentes interpretó el topónimo como un compuesto de la raíz prelatina urr- 'avellano' ( $c f r$. en vasco, urra) y el sufijo -eia, resultado a su vez de la voz - egia 'ladera' ( $c f r$. en catalán -eja). A juicio de este autor, Orreia, Urreia sería una voz vascoide cuyo significado equivaldría a 'ladera de los avellanos' ${ }^{64}$, haciendo extensible esta explicación a todos los topónimos de la serie relacionados en el párrafo anterior.

A nuestro juicio, se ha abusado de la voz vasca urra 'avellano' y de sus derivados para explicar los topónimos del tipo que comentamos, llegando incluso a extender esta explicación a zonas muy alejadas del ámbito lingüístico del euskera ${ }^{65}$, sobre todo si tenemos en cuenta la existencia de la raíz

63.- Cfr. lo expuesto en Emilio Nieto Ballester, Breve diccionario de topónimos españoles, Madrid, Alianza Editorial, 1997, pp. 102-103, v. Calahorra.

64.- A. Galmés, ob. cit., pp. 143-144.

65.- Estas reticencias fueron expresadas ya en 1997 por E. NiETo en su Breve diccionario de topónimos españoles, ob. cit., p. 69, a propósito de los topónimos vascos Urretxu y Urritzola: "No estamos seguros de que deban ser relacionados con el término vasco los diferentes Urrea que encontramos lejos del territorio de lengua vasca en casos como Urrea de Gaén (Teruel), Urrea de Jalón (Zaragoza), etc.”. 
hidronímica *ur- 'agua' que ha dado lugar a una larga serie toponímica que podría ofrecer resultados similares ${ }^{66}$.

A nuestro juicio, y dado que la presencia del agua no es el dato físico más relevante del lugar, no cabe descartar la hipótesis antroponímica, lo que estaría en consonancia con buena parte de las antiguas villas hispano-romanas distribuidas a lo largo de los cauces de los Arbas que son reveladas por la toponimia. En nuestro caso podemos partir del cognomen URIA ${ }^{67}$, sobre el que debemos señalar los siguientes fenómenos fonéticos:

a) En toponimia muchos de los dobletes $-r$ - / -rr- (Uria / Urria) son simples variantes fonéticas del mismo topónimo (cfr. Orio / Orrio).

b) Cierre vocálico de la vocal tónica /o/ en /u/ (Urria > Orria) (cfr. Val de Orrio > Valdurrio).

c) La ya comentada prótesis de la velar sonora /g/ (Orria $>$ Gorria $)$.

d) La apertura articulatoria de /i/ > /e/ del diptongo átono -ia- > -ea(Gorria $>$ Gurrea), con la consiguiente dislocación acentual.

\section{Illo Baio}

Se corresponde con El Bayo, topónimo que en la actualidad también da nombre a uno de los núcleos de colonización de Ejea creados a raíz de la puesta en funcionamiento del Canal de las Bardenas en $1958^{68}$.

El Bayo está situado al oeste de Ejea de los Caballeros sobre un cerro que preside la ribera del río Riguel, en cuya cima amesetada todavía quedan algunos restos de la antigua iglesia del lugar y de dos torreones conocidos como las Torres de El Bayo ${ }^{69}$.

66.- Vid. Francisco Villar Liébana, Indoeuropeos y no indoeuropeos en la Hispania Prerromana, Salamanca, Universidad de Salamanca, Acta Salmanticensia, 2000, pp. 189-208. Cfr. los siguientes topónimos antiguos Ura, Uria, Ora, Oria. Frente a otras adscripciones lingüísticas, F. Villar defiende en este trabajo la indoeuropeidad de ur- a partir de la raíz *uer- / *uor- / *ur- 'agua, corriente, río' ('Wasser, Regen, Fluß' a partir de Hans Krahe, Unsere Ältesten Flussnamen, Otto Harrasswitz, Wiesbaden, 1964, p. 38).

67.- B. LöRINCZ, ob. cit., vol. IV, p. 186. Llegaríamos a idénticos resultados partiendo de cognomina del tipo Aurio o Aureus (Solin \& Salomies, ob. cit., p. 299; B. LöRINCZ, ob. cit. vol. I, p. 105; I. Kajanto, ob. cit., p. 340, Cognomina obtained from inanimate nature and from objects. 2. Material words) que han dado lugar a topónimos como Orrio, Orrios. Vid. sobre esta cuestión lo expuesto en M. Cortés, Toponimia de las Cinco Villas, ob. cit., p. 175, v. Orrio.

68.- Sobre la toponimia de los pueblos de colonización creados a mediados del siglo XX vid. M. CorTÉs, Toponimia de las Cinco Villas de Aragón, ob. cit., pp. 211-224. El Bayo se comenta en pp. 217-218.

69.- Una descripción de estos restos materiales y de otros hallazgos arqueológicos localizados en $E l$ Bayo se encuentra en el trabajo de José FABre Murillo, «La corona de El Bayo», Suessetania, ${ }^{\circ}$ 21 (2003), pp. 74-82. 
A pesar de que se han propuesto etimologías muy diversas ${ }^{70}$, la interpretación más sólida nos conduce a la raíz preindoeuropea *ibai 'vega, río', con temprana pérdida de la vocal inicial $\langle i-\rangle^{71}$ : *(i)bai-o $\rangle$ Bayo.

Semánticamente, el significado de la base léxica *ibai ‘vega, río’ se corresponde plenamente con la realidad nombrada y con la localización del topónimo junto al río Riguel $^{72}$.

Nótese, por último, que desde su primera mención documental (1110) el topónimo va siempre acompañado por el artículo: illo Baio > El Bayo.

\section{CONCLUSIONES}

Desde el punto de vista de la estratigrafía lexical, los topónimos que figuran en la Carta de Población son un reflejo de todas las culturas que se han sucedido a lo largo del tiempo en el territorio de la actual villa de Ejea de los Caballeros.

De la etapa anterior a la colonización romana sobreviven como fósiles linguiísticos voces prelatinas que dieron lugar a topónimos como Barchaona o illo Baio, nombres que encierran nociones espaciales relativas a la depresión del terreno en el primer caso (*barc-) y al cauce del agua en el segundo (*ibai). Más dudas nos ofrece la filiación linguiística de los topónimos Bardena y Gorria; en todo caso, ambos encuentran dificultades para ser explicados por el latín o por cualquiera de las lenguas romances que posteriormente se fueron creando en la Península.

Por su parte, Almalel nos depara uno de los escasísimos topónimos de origen árabe en las Cinco Villas de Aragón, territorio en donde la etapa árabe presentó unas características singulares debido a su temprana constitución como tierra de frontera o extrematura.

El resto de los topónimos mencionados en la Carta de Población tienen un origen latino.

Unos se explican por la vía apelativa a partir de voces comunes como CANALEM 'canal'; CAPĪTIA 'cabeza, cabo'; CASTELLIŌNEM 'castillo pequeño'; FRAXINU 'fresno'; RĪPAM 'ribera'; TŬRREM 'torre'; VALLEM 'valle, val'. Algu-

70.- Vid. un resumen de la cuestión en M. ConTÉs, Toponimia de las Cinco Villas, ob. cit., pp. 115-116.

71.- Compárese esta misma pérdida, por ejemplo, en topónimos como Ilerda > Lérida; Iluro > Lora; Ilurcis > Lorca. Vid. A. GALmés, ob. cit., pp.18-119.

72.- De hecho, en el léxico del riego de algunas zonas de Aragón la voz vallo —o su variante vallaoposee valor apelativo con distintas acepciones, pero todas referidas a la noción de 'cauce de agua

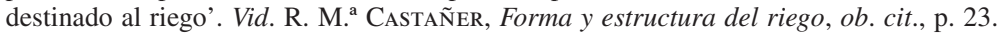


nos de estos apelativos, a su vez, incorporan por medio de adjetivos nociones morfológicas como LŎNGA 'larga' (Torr Longa) o cromáticas como RUBĚAM 'roja' (Arripa Roia).

Otros, sin embargo, encuentran su explicación por la vía antroponímica. El estudio toponomástico de la Carta de Población de 1110 nos ha permitido identificar algunas de las antiguas villas o haciendas que se diseminaban a lo largo de los cauces de los ríos y junto a las principales vías de comunicación de época romana. Todas ellas portan el nombre o sobrenombre del propietario o poseedor de la misma, pudiéndose establecer dos clases de antropónimos según sus características morfológicas.

Contamos, por un lado, con antropónimos no adjetivados procedentes del nominativo o del acusativo: Axsillius, AsIllius > Capeza d'Aquisilio; IASSA > Castejón de Valdejasa; Sentia > Santia; y, según la interpretación que hemos propuesto, URIA > Gorria. Por otro, encontramos antropónimos adjetivados por medio de distintas sufijaciones: el sufijo -ĚsSA en el caso de [VILLA] ANNIESSA (de AnNius) > Añesa; el sufijo -o/-ONIS (de Scaurus) en Escoron.

Desde el punto de vista semántico, y dejando aparte por su especificidad los topónimos de carácter antroponímico, la mayor parte de los nombres de lugar que figuran en el documento responde a nociones espaciales elementales que están presentes sobre el terreno.

Cuantitativamente el grupo más numeroso está constituido por los topónimos castrales formados sobre el apelativo TŬRREM 'torre' (Torr de Escoron, Torr de Canals, Torr de Annessa, Torr Longa, Torr de Sentia y Torr de Arripas), al que debemos sumar Castillon de Baldeiassa (de CASTELlōNem 'castillo pequeño'). En un territorio fronterizo como era la Exea de julio de 1110 , las edificaciones de carácter defensivo se constituyen en un elemento deíctico de primer orden a la hora de configurar y ordenar el territorio, hasta el punto de que el resto de elementos identificadores - Escoron, Canals, Annessa, Longa, Sentia, Arripas-, aun siendo nombres preexistentes, se subordinan a este elemento primordial.

Destacan, en segundo lugar, los fitotopónimos formados sobre el apelativo FRAXINU 'fresno', bien sea por su singularidad en el paisaje (Fraxino de rio de Ores, Fraxino de rio de Aonna), o bien por su carácter colectivo (Fraxinat, Fraxinatello). Aunque con un carácter más genérico y no focalizado en ninguna especie concreta, entran dentro de los fitotopónimos nociones como las expresadas por Bardena o Almalel en referencia a su condición de 'lugares de pasto'.

El hábitat natural del fresno junto a los cauces fluviales explica su aparición conjunta con el nombre de los ríos que surcan el territorio (rio de 
Aonna, rio de Ores). Este mismo motivo acuático está en el origen de los dos topónimos señalizadores del espacio próximo como son Arripas o Arripa Roia. Sin embargo, los dos únicos hidrotopónimos puros del corpus analizado son illo Baio y Canals.

El resto de topónimos citados componen una dispar suerte de morfotopónimos: uno está referido a las depresiones del terreno como Barchaona; otro cae del lado de la oronimia (Capeza d'Aquisilio); otro sirve para describir la morfología de una edificación (Torr Longa). 
